\title{
Evaluación de las Jornadas de Ambientación y Orientación Pedagógico-institucional para ingresantes a la Facultad de Bioquímica y Ciencias Biológicas y a la Escuela Superior de Sanidad de la UNL
}

Baumann, Nidia Alcira (*) Ibáñez Tres, Leandro Gustavo Miguel (**)

\section{Introducción}

La planificación y organización de las Jornadas de Ambientación estuvieron a nuestro cargo y, en la ejecución, se contó con la ayuda del grupo de alumnos de los centros de estudiantes de la FBCB y de la ESS.

Estuvieron presentes autoridades, coordinadores de cada una de las carreras, docentes de primer año, y el jefe de alumnado. También se contó con la presencia de la Prof. Marcela Manuale.

\section{Planificación}

La planificación de estas jornadas sufrió modificaciones respecto de años anteriores debido al importante número de ingresantes que se incorporó, aportado por las carreras de la ESS y por la Licenciatura en Nutrición, que es una nueva propuesta de grado que dicta la FBCB a partir del corriente año académico.

Tanto la organización, como la planificación debieron ajustarse en tiempo, porque no se contaba con la disponibilidad semanal necesaria para ejecutarlas y ponerlas en marcha, por los motivos que a continuación detallamos: los exámenes recuperatorios del ingreso estaban fijados en días puntuales y la facultad iniciaba su calendario académico completo, por lo tanto, no era posible contar con el espacio físico necesario, como tampoco con la colaboración y participación de los alumnos de los centros de estudiantes que comenzaban el cursado. Ante esta situación 
limitada en lo temporo-espacial, se decidió replanificarlas y llevarlas a cabo con una duración de 5 hs. por carrera y por Jornada, cuando anteriormente se ejecutaron durante 5 días con un total de 15 hs. distribuidas en 3 hs. diarias.

Los programas fueron los mismos para todos los días y para todas las carreras, aunque cada una tuvo su orientación específica con argumentos de coincidencias y diferencias. La distribución de las carreras fue la siguiente:

- Bioquímica y Licenciatura en Biotecnología

- Licenciatura en Nutrición

- Terapia Ocupacional

- Licenciatura en Administración de la Salud, Licenciatura en Higiene y Seguridad en el trabajo, y Licenciatura en Saneamiento Ambiental

Cada grupo contaba con aproximadamente 250 ingresantes; el número total fue cercano a los 1200. Se trabajó de mañana para las carreras de la FBCB y en el turno vespertino para las carreras de la ESS.

Cada Jornada se desarrolló de la siguiente manera:

a) Recepción por parte de las autoridades

b) Explicación del uso de los servicios de la sección alumnado

c) Recorrido por la Facultad

d) Trabajo en el aula con temáticas de búsqueda de coincidencias y diferencias en lo personal, en lo institucional, y en lo profesional-laboral

\section{Contenidos y ejecución}

a) Lo Personal

El encuadre teórico de los encuentros tuvo que ver con que los ingresantes pudieran encontrar coincidencias y diferencias, reflexionando en pequeños grupos su problemática personal que se focalizó en los siguientes tópicos:

- Miedos y Esperanzas

- Motivos de Elección

- Ética y Valores

Se trató de este modo de acompañar a los jóvenes para que pudieran con su grupo de pares pensar-se:

- Quién y cómo elige y decide

- Sus expectativas

- Sus dudas, temores e inseguridades

- Sus valores

En la puesta en común como trabajo de síntesis este año la propuesta se cerró 
solamente con intercambio verbal, ya que no fue posible programar producciones escritas por el limitado tiempo del que se disponía.

De lo expuesto, surgen coincidencias y deferencias:

1. Cada sujeto es una persona singular y distinta;

2. la situación de elegir se realiza desde una historia y una perspectiva individual que implica una conclusión subjetiva producida a partir de las relaciones con otras personas y a través de influencias externas en un determinado contexto social;

3. hoy sienten temores, dudas e inseguridades que tienen que ver con ellos mismos, y con los motivos de elección-decisión asumidos en esta situación nueva y de cambio que se les presenta, tal como el inicio de una carrera universitaria lo que implica todo un desafío;

4. deben detectar esos temores, dudas e inseguridades para que los movilicen a buscar su equilibrio, su respuesta, y trabajar así en la búsqueda de la esperanza para que este inicio sea fructífero;

5. son protagonistas;

6. los valores y la ética completan y rigen la vida y la profesión dado que ésta forma parte de nuestra identidad;

\section{b) Lo institucional}

Puntualizando siempre que el ingresante necesita conocer datos de la realidad se le brindó información de lo institucional tanto en sus aspectos físico, pedagógico y académico, como en el vincular social.

Los recursos utilizados fueron:

- El recorrido por la Facultad donde descubre sus distintas dependencias y funcionalidad;

- en el panel compuesto por autoridades, coordinadores y docentes se expuso una síntesis de cada carrera: su definición y ubicación dentro de las áreas de conocimiento a la que pertenece, planificación de las mismas con ciclo básico y especialización; horarios, tipos de clases (teóricas, coloquios, TP), exámenes parciales y finales. Del mismo participó el jefe de alumnado, quien transmitió a los ingresantes los requisitos y exigencias que deben gestionar como alumnos en esta dependencia.

Los docentes de la ESS para este aspecto utilizaron como recurso didáctico la proyección de transparencias.

Como evaluación de este aspecto podemos manifestar que se logró el objetivo buscado, de que los ingresantes reflexionaran que: se capacitan cursando una carrera profesional para construir y concretar su identidad personal y ocupacional. 
Vale agregar que este año se abordó la temática buscando coincidencias y diferencias dado que se incorporaron las carreras de la ESS y la Licenciatura en Nutrición.

\section{c) El trabajo}

La síntesis del contenido de este núcleo se logró por parte de los ingresantes a través de la información brindada por los coordinadores y graduados quienes les transmitieron sus experiencias profesionales, laborales y personales.

A través de testimonios, otros usando material de proyecciones les facilitaron a los alumnos:

- Conceptuar, elaborar, interpretar las distintas posibilidades que socialmente presenta una realidad ocupacional compleja y dinámica, que no es ajena a una concepción del hombre y del mundo, mucho menos al pasado, presente y futuro del país, en suma de una sociedad;

- considerar al sistema productivo de esta sociedad, de este país como un conjunto de elementos y de relaciones que de una forma u otra, de una manera específica engarza lo económico, lo ideológico y el poder;

- que debe interpretar sus gustos, intereses, capacidad, en suma su interior, para elegir un lugar en el mundo de la producción en términos de una profesión, de un trabajo;

- que conocer y conocer-se lo moviliza efectivamente, según su singularidad para ser y hacer, partiendo de una realidad social compleja, mutante y dinámica a: a) resolver problemas, y b) satisfacer necesidades;

- conocer su futura actuación profesional: a) incumbencias y/o funciones, b) tareas, c) instrumentos, d) objeto, e) ámbitos, f) interdisciplina, g) valores, h) ética.

Se trabajó la temática con lectura de textos literarios que funcionaron como disparadores, abordando los distintos grupos a conclusiones finales, que compartieron en una puesta en común.

\section{Conclusiones}

Como conclusiones podemos destacar que, en relación a años anteriores, se ha trabajado menos tiempo con los alumnos debido al alto número de ingresantes, lo cual significó que estas Jornadas no fueran tan productivas en relación al acercamiento de la institución en lo individual, como en lo grupal.

Como síntesis de la evaluación de los contenidos es válido rescatar la importancia de los mismos, su significación y recepción positiva por parte de los jóvenes. 
Se debe tener en cuenta, como propuesta enriquecedora y valiosa, que éste fue el primer año de trabajo en conjunto con la ESS, que enriqueció al aprendizaje de la diversidad de las carreras, en cuanto a sus similitudes y diferencias, aun tratándose de aquellas que tienen ejes científicos comunes. 